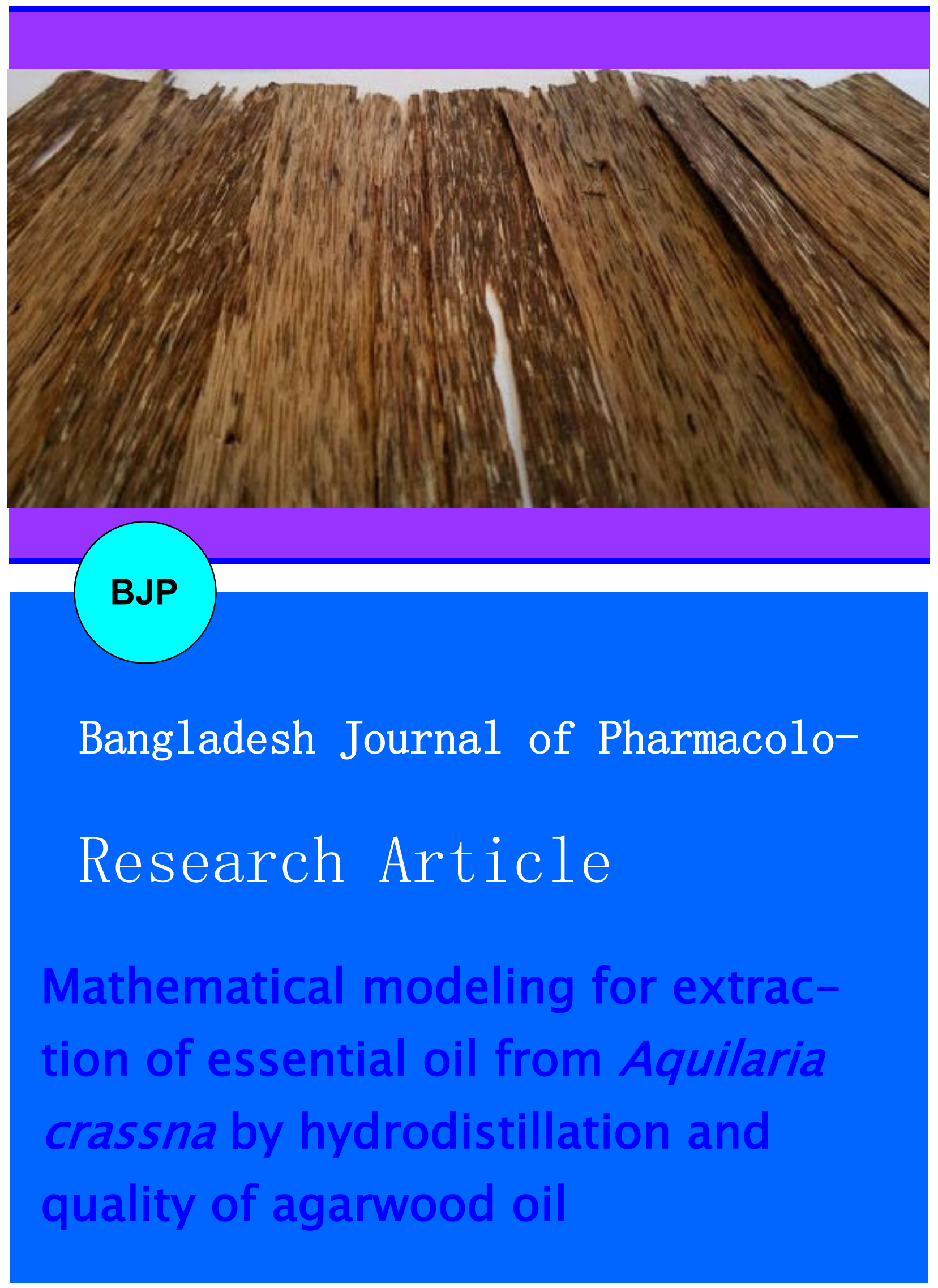




\title{
Mathematical modeling for extraction of essential oil from Aquilaria crassna by hydrodistillation and quality of agarwood oil
}

\section{Jutarut Pornpunyapat, Pakamas Chetpattananondh and Chakrit Tongurai}

\author{
Department of Chemical Engineering, Faculty of Engineering, Prince of Songkla University,
} Hat Yai, Songkhla 90112, Thailand.

\begin{tabular}{|c|c|}
\hline \multicolumn{2}{|l|}{ Article Info } \\
\hline Received: & 29 June 2011 \\
\hline Accepted: & 30 June 2011 \\
\hline Available Online: & 3 July 2011 \\
\hline \multicolumn{2}{|c|}{ DOI: 10.3329/bjp.v6i1.7902 } \\
\hline \multicolumn{2}{|c|}{$\begin{array}{l}\text { Cite this article: } \\
\text { Pornpunyapat J, Chetpattananondh P, } \\
\text { Tongurai C. Mathematical modeling } \\
\text { for extraction of essential oil from } \\
\text { Aquilaria crassna by hydrodistillation } \\
\text { and quality of agarwood oil. Bangla- } \\
\text { desh J Pharmacol. } 2011 ; 6: 18-24 \text {. }\end{array}$} \\
\hline
\end{tabular}

\begin{abstract}
Agarwood oil is widely used in medicine, perfume and cosmetic industries due to its unique properties and high medicinal value. However, knowledge on distillation process and standard for quality of the oil are far from sufficient. In this work, agarwood oil was hydrodistilled at various temperatures in order to study the distillation kinetics and quality of the oil. Higher oil yield and better quality of the oil were obtained at higher operating temperature. The mechanism of oil hydrodistillation consisted of two stages: washing stage and diffusion stage. The diffusion stage was the controlling step of oil hydrodistillation. Both mass transfer kinetic coefficients increased with increasing distillation temperatures. The oil gain at a higher temperature had a darker color and seemed to stick longer to the human skin. The different physical properties of the oil were a result of different chemical constituents exhibited in GC-MS profiles.
\end{abstract}

\section{Introduction}

Agarwood (gaharu, eaglewood, aloeswood, oud, chenxiang and jinkoh) is a fragrant and highly valuable wood found in Aquilaria species of the Thymelaeaceae family. There are 15 species of agarwood, but mostly three species are found in Thailand: Aquilaria crassna, A. subintegra and A. malaccensis. Agarwood is traded in various forms, including tree trunks and large branches, chips and flakes of uniform quality, powder, and essential oil (Pojanagaroon and Kaewrak, 2005). The oil has three principal uses: medicines, perfumes and incense. It is used as incense as well as a traditional sedative, analgesic and digestive medicine in traditional Chinese and Japanese medicine (Liu et al., 2008; Abdullah et al., 2007). In Egypt, Arabia and throughout the northeast part of Bangladesh, agarwood is described as a stimulant, cardiac tonic and carminative (Bhuiyan et al., 2009). Furthermore, it has been used for centuries as incense in Buddhist, Hindu and Islamic ceremonies (Naef, 2011). It is also a highly demanded ingredient in fine perfumery for its warm, unique balsamic notes with sandalwood-ambergris tonalities.

Various techniques have been used for agarwood oil extraction: water distillation (hydrodistillation), steam distillation, solvent extraction, and supercritical fluid extraction (Naef, 2011). Each technique has particular advantages and disadvantages. Nevertheless, agarwood oil is most frequently obtained by hydrodistillation because it is safe to operate and environmentally friendly (Liu et al., 2008). Moreover, in hydrodistillation the plant material is completely immersed in boiling water. Then the surrounding water acts as a barrier to protect the oil from overheating (Sovová and Aleksovski, 2006).

In the traditional agarwood oil distillation, process efficiency is low. Furthermore, the kinetic data of agarwood oil distillation is very rare. Study of mathematical model of distillation kinetic could improve distillation process without the need to run too many experiments (Cassel et al., 2009). By modeling the 
kinetics of distillation, one can contribute not only to the fundamental understanding of the process but also to its better control and higher efficiency. Cassel et al. (2009) studied steam distillation modelling for essential oil extraction from rosemary (Rosmarinus officinalis), basil (Ocimum basilicum) and lavender (Lavandula dentate). Their kinetic model fitted very well with their experimental data and the model parameters could be useful during the scale-up of the extraction process. Koul et al. (2004) developed a simple first order kinetic model for steam distillation of lemongrass. The behaviour of oil production inside the distillation unit is not instantaneous, but it requires time for grass wetting, diffusion and osmosis of oil.

The models for steam distillation and hydrodistillation consider essential oil as one pseudo-component and most of them assume that diffusion of the solute to the particle surface is the controlling step. Milojevič et al. (2008) investigated the hydrodistillation kinetics of essential oil from comminuted ripe juniper berries (Juniperus communis) using a two-parameter model of unsteady-state diffusion through the plant material. The model was well correlated with their experimental results.

One of the major limiting factors of increasing trade and market penetration of agarwood oil has been a lack of quality standards. Hidayat et al. (2010) reported that agarwood oil grading has been traditionally performed by trained human graders (sensory panels). The disadvantages of this technique include subjectivity, poor reproducibility, time consumption and large labor expense (Keller, 1999). A human nose cannot tolerate a high number of samples and work in continuous production because it fatigues rapidly with increasing number of samples (Hidayat et al., 2010; Keller, 1999). Identification of agarwood oil would seem to be impossible without the use of laboratory techniques (Barden et al., 2000). However, in the trading market agarwood oil is graded according to the basic specification, such as the oleoresin content, the color and the aroma/smell.

The objective of this study is to investigate the effect of distillation temperature on extraction of agarwood oil from A. crassna in terms of oil yield and oil quality (physical properties and chemical composition). Then a developed mass transfer mathematical model is validated with the experimental results to describe the process behavior.

\section{Materials and Methods}

Plant material: The wood of A. crassna was obtained from Kritsana Cooperative Club, Trat, Thailand. The plants were grown for 7 years before resin activated for 2 years and then harvested. The wood was dried until the moisture content was 3\% (dry basis) before being milled and sieved to a size of $0.7 \mathrm{~cm}$.

Extraction of essential oil: The comminuted wood $(3,000$ g) was soaked in distilled water $(27,000 \mathrm{~g})$ for up to $7 \mathrm{~d}$ (Liu et al., 2008; Bhuiyan et al., 2009) in order to break down the parenchymatous and oil glands. This ratio of agarwood to distilled water (1:9) is usually applied in the industrial production of agarwood oil. The soaked agarwood was then placed with water into a distillation apparatus. Hydrodistillation was operated at various temperatures: 80,100 and $120^{\circ} \mathrm{C}$. The distillation temperature was not higher than $120^{\circ} \mathrm{C}$ to prevent burning of plant material. During distillation the vapor, composed of steam and volatile compounds, rises from the extractor to the condenser, where the two immiscible liquid phases, namely aromatic water and agarwood oil, are formed. In the separator, the lighter agarwood oil is separated from the aromatic water, which returns to the extractor via a recycle pipe. Agarwood oil was collected every 8 hours and left in the separator funnel for essential oil separation. The distillation was conducted in triplicates and the average values are presented.

The distillation unit consists of four major components (Figure 1): a stainless steel extractor with an inner diameter of $0.4 \mathrm{~m}$ and a height of $0.5 \mathrm{~m}$, a stainless steel condenser with an inner diameter of $0.4 \mathrm{~m}$ and a height of $1.2 \mathrm{~m}$, a stainless steel separator with an inner diameter of $0.3 \mathrm{~m}$ and a height of $1.2 \mathrm{~m}$, and a cooling tower driven by a $1.5 \mathrm{~kW}$ motor. The extractor was heated by using a gas stove which was connected to a controller with an accuracy of $\pm 0.1^{\circ} \mathrm{C}$ to control the gas usage and extraction temperature.

Study of distillation kinetic model: The mass transport of essential oil through plant particles during hydrodistillation occurs as unsteady-state diffusion. The diffusion of the solute to the particle surface is assumed to be the controlling step. For batch hydrodistillation and no chemical reaction, Fick's second law (Equation 1) of one -dimensional unsteady-state diffusion can be applied.

$$
\frac{\partial q_{p}}{\partial t}=D_{e f f} \frac{\partial^{2} q_{p}}{\partial x^{2}}
$$

Where $q_{p}$ is the average concentration of essential oil in the plant particles at time $t, x$ is the distance along the direction of diffusion, and $D_{\text {eff }}$ is the effective diffusion coefficient. The following assumptions at the level of plant particles in the suspension should be made to solve Equation 1:

1) The plant particles are isotropic, equal in size and do not change their size and shape during the hydrodistillation; 


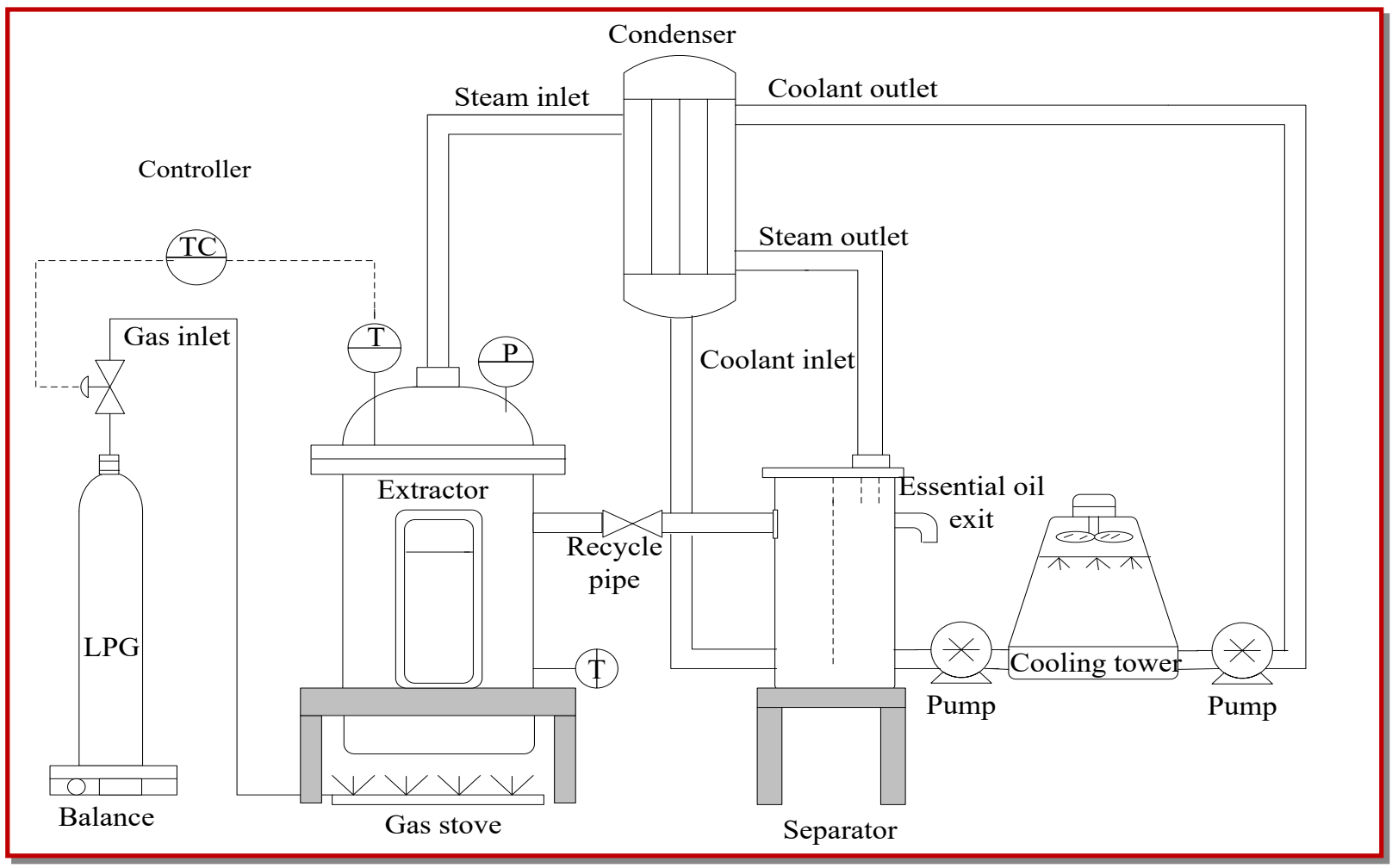

Figure 1: The extractor apparatus

2) The essential oil is considered as a pseudocomponent.

3) A part of essential oil is located at the external surfaces of the broken agarwood and the rest is uniformly distributed in the plant particles.

4) The effective diffusion coefficient is constant.

5) The concentration of essential oil on the external surfaces of the plant particles at any moment during the distillation is zero because of its instantaneous "washing" from the surface.

6) the resistance to the mass transport of essential oil from the external surface of the plant particles is assumed to be zero.

Integrating Eq. (1) with the above suitable initial and boundary conditions (Treybal, 1975) leads to Equation 2:

$$
\frac{\left(q_{0}-q\right)}{q_{0}}=A \cdot e^{-k t}
$$

Where, $q$ is the average yield of agarwood oil at time $t$, $q_{0}$ is the initial average concentration of agarwood oil (found by extraction with hexane in a Soxhlet apparatus), $A$ is a constant, and $k$ is a kinetic constant including the effective diffusion coefficient.

Based on this model, the extraction of agarwood oil by hydrodistillation consists of two successive stages, a washing stage and diffusion stage, as proposed by Milojevič et al. (2008):

In washing stage, the essential oil is washed from and near the external surface of the plant particles during an initial, short period of distillation (theoretically at $t=0$ ). It can be characterized by a rapid increase in the oil yield at the very beginning of the process (Equation 3):

$$
t=0: q=q_{w} \text { or } \frac{q}{q_{0}}=\frac{q_{w}}{q_{0}}=b
$$

Where, at $t=0 ; q_{w}$ is the essential oil yield and $b$ is the relative amount of essential oil extracted.

In diffusion stage, the essential oil diffuses from the interior of the plant particles towards their external surfaces followed by its distillation. It is characterized by a slow exponential increase in the oil yield with the progress of distillation. The basic kinetic equation for agarwood oil hydrodistillation was derived by combining Equation 2 and 3 as shown in Equation 4:

$$
\frac{\left(q_{0}-q\right)}{q_{0}}=(1-b) \cdot e^{-k t}
$$


In this proposed model, $b$ is called a washing coefficient and $k$ is called a diffusion coefficient. The linearized form of the equation can be used to calculate the parameters of Equation 4:

$$
\ln \left(\frac{q_{0}-q}{q_{0}}\right)=\ln (1-b)-k t
$$

Study of physical properties: Relative density and refractive index were analyzed using two standard procedures: ISO 279, a method for determining the relative density of essential oils (ISO, 1998); and ISO 280, a method for determining the refractive index of essential oils (ISO, 1998). Surface tension was determined by a tensiometer (Model OS, Torsion, UK).

Study of chemical compounds by GC-MS: Agarwood oil composition was studied by GC-MS analysis using a Hewlett Packard gas chromatograph (GC 5890) coupled with a mass selective detector (5972) (Hewlett Packard, Palo Alto, USA). Separation of the analytes by gas chromatography was carried out using a silica capillary column (30 m length, $0.25 \mathrm{~mm}$ diameter, $0.25 \mathrm{~mm}$ film thickness) of HP-5MS (Hewlett Packard). Separation of the compounds involved injection of $1.0 \mathrm{~mL}$ of the oil into the front inlet of the gas chromatograph operating at $250^{\circ} \mathrm{C}$ in the splitless mode. The flow rate of the carrier gas, helium, was $2.0 \mathrm{~mL} / \mathrm{min}$ with a 1:50 split ratio. The oven program commenced at $80^{\circ} \mathrm{C}$, where it was held for $2 \mathrm{~min}$ and then increased at a rate of $10^{\circ} \mathrm{C} /$ min to $250^{\circ} \mathrm{C}$, where it was held for $10 \mathrm{~min}$. The interface temperature was $250^{\circ} \mathrm{C}$. Ionization of the analytes by electron impact (EI) was obtained using an emission current of $70 \mathrm{eV}$. The ion source temperature was set at $250^{\circ} \mathrm{C}$ and the scan scope was set from 32 to 500 amu. The compounds were characterized by database matching and comparison of their MS spectra with existing data in the Wiley and Adams library search data (Adam, 2001).

\section{Results and Discussion}

From soxhlet extraction the initial average concentration of agarwood oil was $1000 \mathrm{mg} / \mathrm{g}$. With hydrodistillation for 64 hours the average agarwood oil yields at temperatures of 120,100 and $80^{\circ} \mathrm{C}$ were 611.7 , 515.3 and $455.3 \mathrm{mg} / \mathrm{g}$ dried wood, respectively. The oil yields at various distillation temperatures as a function of distillation time are shown in Figure 2. It was notable that the curves are typical for the hydrodistillation of essential oils from aromatic plant materials and verify the proposed mechanism of oil isolation (Milojevič et al., 2008). The mechanism consisted of two stages: fast oil distillation and slow oil distillation. The oil yield increased rapidly during the initial stage because the oil was rapidly washed from the external surfaces of the

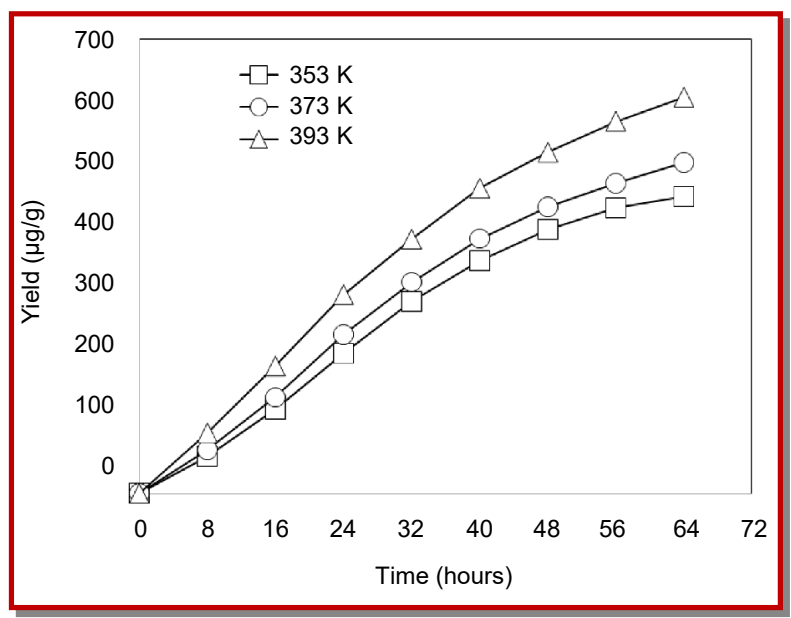

Figure 2: Yield of essential oil at various distillation temperatures

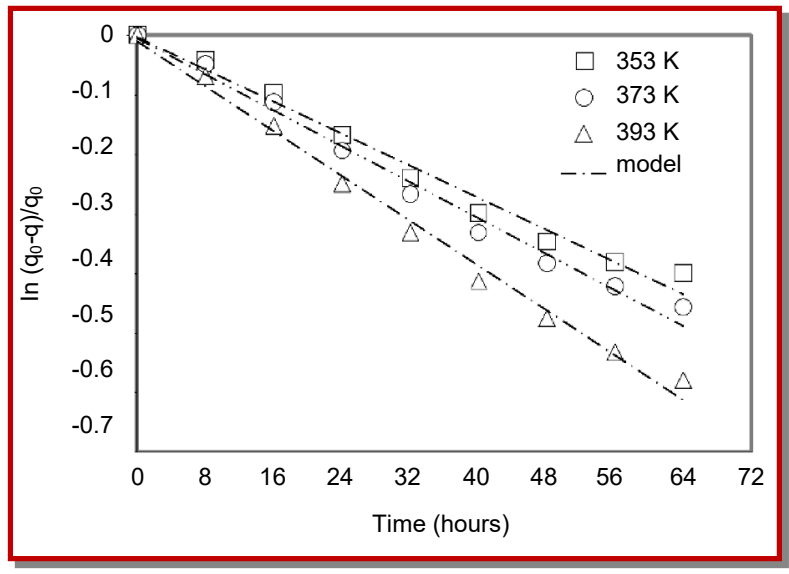

Figure 3: Kinetics of essential oil from experimental data fitted to the mass transfer kinetic model at various distillation temperatures

wood during short period of hydrodistillation. This is called fast oil distillation stage. In the latter stage (slow oil distillation), the extraction rate gradually slowed down until nearly constant as a result of diffusion of oil from interior of the wood towards it surface.

The dependence of $\ln \left[\left(q_{0}-q\right) / q_{0}\right]$ versus time is shown in Figure 3. It can be seen that Equation 5 described the experimental data quite well. This result confirms that the hydrodistillation of agarwood oil was controlled by diffusion stage. The operation with a small particle size of wood and long soaking time might help to promote the distillation efficiency. The parameters of the kinetic model, $b$ and $k$, were calculated from the experimental data by means of linear regression method using Equation 5, as shown in Table I.

The relationship of washing coefficient $(b)$ and diffusion coefficient $(k)$ on the distillation temperature can be expressed as shown in Equation 6 and 7 respectively. 


\begin{tabular}{|lccc|}
\hline \multicolumn{4}{|c|}{ Table I } \\
\hline \multicolumn{4}{|c|}{ Parameters of kinetic model at various tempera- } \\
tures \\
\hline $\mathrm{T}(\mathrm{K})$ & $\mathrm{k}\left(\mathrm{h}^{-1}\right)$ & $\mathrm{b}(\mathrm{l})$ & $\mathrm{R}^{2}$ \\
\hline 353 & 0.0055 & 0.019 & 0.95 \\
373 & 0.0063 & 0.022 & 0.96 \\
393 & 0.0087 & 0.025 & 0.97 \\
\hline
\end{tabular}

$k=8.0 \times 10^{-5} T-0.023$

$b=1.5 \times 10^{-4} T-0.033$

$$
b=1.5 \times 10^{-4} T-0.033
$$

Where, $T$ is the distillation temperature $(\mathrm{K})$; the coefficients of linear correlation of $k$ and $b$ were 0.92 and 1.00 , respectively

Both kinetic parameters increased with increasing distillation temperatures. This result implies that the oil was washed and diffused from the wood faster at higher temperatures as the diffusivities and driving forces of solute (oil) and solvent increased (Mani et al., 2007).

Physical properties of agarwood oils distilled at various temperatures are shown in Table II. It is noticeable that higher values of refractive index, relative density and surface tension were observed at higher operating temperatures. The oil with higher refractive index presents darker color. The oil with greater relative density is assumed to contain higher amount of aroma resinous compounds that distinguishes agarwood oil from the others. The oil with greater surface tension shows higher strength and longevity of the oil fragrance. With higher surface tension, the oil seems to stick longer to human skin. With these physical properties along with the smell agarwood oil can be simply graded. In addition, the agarwood oil quality can be basically tested according to some assumptions: pure agarwood oil will not give different color at the

\begin{tabular}{|c|c|c|c|}
\hline \multicolumn{4}{|c|}{ Table II } \\
\hline \multicolumn{4}{|c|}{$\begin{array}{c}\text { Physical properties of agarwood oil at various tem- } \\
\text { peratures }\end{array}$} \\
\hline $\mathrm{T}\left({ }^{\circ} \mathrm{C}\right)$ & $\begin{array}{c}\text { Relative } \\
\text { density at } \\
20^{\circ} \mathrm{C}\end{array}$ & $\begin{array}{l}\text { Refractive in- } \\
\text { dex at } 20^{\circ} \mathrm{C}\end{array}$ & $\begin{array}{l}\text { Surface ten- } \\
\text { sion (dynes/ } \\
\mathrm{cm})\end{array}$ \\
\hline 80 & $0.94 \pm 0.01^{\mathrm{a}}$ & $1.480 \pm 0.002^{\mathrm{d}}$ & $32.8 \pm 0.2 \mathrm{~g}$ \\
\hline 100 & $0.96 \pm 0.02^{b}$ & $1.500 \pm 0.003^{e}$ & $34.4 \pm 0.4^{\mathrm{h}}$ \\
\hline 120 & $0.98 \pm 0.005^{c}$ & $1.525 \pm 0.003^{f}$ & $36.9 \pm 0.2^{\mathrm{i}}$ \\
\hline \multicolumn{4}{|c|}{$\begin{array}{l}\text { Data were reported in means } \pm \text { standard deviation. Values within } \\
\text { the same column followed by different letter in each column are } \\
\text { significantly difference }(p<0.05)\end{array}$} \\
\hline
\end{tabular}

base and surface inside the bottle; when put the oil in front of the high power lamp the shining light from the bulb cannot see trough; the oil should remain on hand more than 5 hours; and the very finest agarwood oil will sink in water.

From GC-MS analyses the agarwood oil distilled at 120, 100 and $80^{\circ} \mathrm{C}$ gave the major compounds of 21,13 and 8 , respectively. This indicates that distillation temperature had an effect on chemical compounds of extracted oil. At higher distillation temperature, the oil components with higher boiling point can be extracted as a result of a higher number of chemical compounds. As shown in Table III, agarospirol, alloaromadendrene, valencene and valerenol were the major compounds (chromatogram area $>6 \%$ ) of the oil hydrodistilled at 80 ${ }^{\circ} \mathrm{C}$. Aristolene, 1,5-diphenyl-3-pentanone and agarospirol were found to be the major compounds of the oil distilled at $100^{\circ} \mathrm{C}$ (Table IV). From Table V, aromadendrenepoxide, agarospirol, alpha-gurjunene and 2naphthaleneethanol were the major compounds of the oil distilled at $120^{\circ} \mathrm{C}$. It is noticed that agarospirol, hexadecanoic acid and 1,5-diphenyl-3-pentanone were found in all oil samples. However, hexadecanoic acid or palmitic acid and 1,5-diphenyl-3-pentanone are not the fragrant agents. Agarospirol was the compound

Table III

Chemical compounds of agarwood oil at $80^{\circ} \mathrm{C}$

\begin{tabular}{|c|c|c|c|c|c|}
\hline No & Chemical compound & $\begin{array}{l}\text { R.T.a }^{a} \\
\text { (min) }\end{array}$ & $\begin{array}{l}\text { R.T.b } \\
\text { (min) }\end{array}$ & Formula & $\begin{array}{c}\text { Chromatogram area } \\
(\%)\end{array}$ \\
\hline 1 & Agarospirol & 14.9 & 14.9 & $\mathrm{C}_{15} \mathrm{H}_{26} \mathrm{O}$ & 7.3 \\
\hline 2 & Alloaromadendrene & 15.2 & 15.1 & $\mathrm{C}_{15} \mathrm{H}_{24}$ & 7.3 \\
\hline 3 & Valencene & 15.3 & 15.3 & $\mathrm{C}_{15} \mathrm{H}_{24}$ & 6.7 \\
\hline 4 & Calarene & 17.4 & 17.4 & $\mathrm{C}_{15} \mathrm{H}_{24}$ & 4.4 \\
\hline 5 & Valerenol & 18.0 & 18.0 & $\mathrm{C}_{15} \mathrm{H}_{24} \mathrm{O}$ & 6.1 \\
\hline 6 & Hexadecanoic acid & 21.1 & 21.1 & $\mathrm{C}_{16} \mathrm{H}_{32} \mathrm{O}_{2}$ & 2.1 \\
\hline 7 & 1,5-Diphenyl-3-pentanone & 22.3 & 22.3 & $\mathrm{C}_{17} \mathrm{H}_{18} \mathrm{O}$ & 2.4 \\
\hline 8 & Octadecanoic & 23.9 & 23.8 & $\mathrm{C}_{18} \mathrm{H}_{36} \mathrm{O}_{2}$ & 2.5 \\
\hline
\end{tabular}

aThe retention time obtained from computer matching against with library; b the retention time obtained from sample as shown in each peak of chromatogram 
Table IV

\begin{tabular}{|c|c|c|c|c|c|}
\hline \multicolumn{6}{|c|}{ Chemical compounds of agarwood oil at $100^{\circ} \mathrm{C}$} \\
\hline No & Chemical compound & $\begin{array}{l}\text { R.T.a } \\
\text { (min) }\end{array}$ & $\begin{array}{l}\text { R.T.b } \\
(\min )\end{array}$ & Formula & $\begin{array}{c}\text { Chromatogram area } \\
(\%)\end{array}$ \\
\hline 1 & Benzofuran & 11.7 & 11.7 & $\mathrm{C}_{9} \mathrm{H}_{8} \mathrm{O}_{2}$ & 0.2 \\
\hline 2 & 10-Epi-gamma-eudesmol & 14.3 & 14.2 & $\mathrm{C}_{15} \mathrm{H}_{26} \mathrm{O}$ & 4.3 \\
\hline 3 & Agarospirol & 14.9 & 14.9 & $\mathrm{C}_{15} \mathrm{H}_{26} \mathrm{O}$ & 6.0 \\
\hline 4 & Calarene & 15.0 & 15.0 & $\mathrm{C}_{15} \mathrm{H}_{24}$ & 1.3 \\
\hline 5 & Aristolene & 15.2 & 15.2 & $\mathrm{C}_{15} \mathrm{H}_{24}$ & 8.0 \\
\hline 6 & Aromadendrene & 15.4 & 15.3 & $\mathrm{C}_{15} \mathrm{H}_{24}$ & 0.9 \\
\hline 7 & deta-Guaiene & 15.7 & 15.7 & $\mathrm{C}_{15} \mathrm{H}_{24}$ & 1.3 \\
\hline 8 & Phenol,2,3,5,6-tetramethyl & 17.0 & 17.0 & $\mathrm{C}_{10} \mathrm{H}_{14} \mathrm{O}$ & 0.7 \\
\hline 9 & alpha-Selinene & 17.7 & 17.7 & $\mathrm{C}_{15} \mathrm{H}_{24}$ & 0.7 \\
\hline 10 & Valerenic acid & 20.4 & 20.4 & $\mathrm{C}_{15} \mathrm{H}_{22} \mathrm{O}_{2}$ & 3.2 \\
\hline 11 & Hexadecanoic acid & 21.1 & 21.0 & $\mathrm{C}_{16} \mathrm{H}_{32} \mathrm{O}_{2}$ & 0.6 \\
\hline 12 & 1,5-Diphenyl-3-pentanone & 22.3 & 22.3 & $\mathrm{C}_{17} \mathrm{H}_{18} \mathrm{O}$ & 7.4 \\
\hline 13 & 1-Penten-3-one & 27.6 & 27.6 & $\mathrm{C}_{17} \mathrm{H}_{16} \mathrm{O}$ & 0.7 \\
\hline
\end{tabular}

\section{Table V}

\begin{tabular}{|c|c|c|c|c|c|}
\hline \multicolumn{6}{|c|}{ Chemical compounds of agarwood oil at $120^{\circ} \mathrm{C}$} \\
\hline No & Chemical compound & $\begin{array}{l}\text { R.T.a }^{\mathrm{a}} \\
\text { (min) }\end{array}$ & $\begin{array}{l}\text { R.T.b } \\
\text { (min) }\end{array}$ & Formula & $\begin{array}{c}\text { Chromatogram area } \\
(\%)\end{array}$ \\
\hline 1 & Spathulenol & 10.3 & 10.3 & $\mathrm{C}_{15} \mathrm{H}_{24} \mathrm{O}$ & 1.1 \\
\hline 2 & Hexanoic acid & 11.5 & 11.5 & $\mathrm{C}_{6} \mathrm{H}_{12} \mathrm{O}_{2}$ & 2.4 \\
\hline 3 & 2-Butanone & 11.8 & 11.8 & $\mathrm{C}_{10} \mathrm{H}_{12} \mathrm{O}$ & 3.1 \\
\hline 4 & alpha-Agarofuran & 12.0 & 12.2 & $\mathrm{C}_{15} \mathrm{H}_{24} \mathrm{O}$ & 2.4 \\
\hline 5 & 10-epi-gamma-Eudesmol & 14.3 & 14.3 & $\mathrm{C}_{15} \mathrm{H}_{26} \mathrm{O}$ & 3.2 \\
\hline 6 & Dihydroneoclovene & 14.7 & 14.7 & $\mathrm{C}_{15} \mathrm{H}_{26}$ & 1.5 \\
\hline 7 & Agarospirol & 14.9 & 14.9 & $\mathrm{C}_{15} \mathrm{H}_{26} \mathrm{O}$ & 8.1 \\
\hline 8 & Valencene & 15.0 & 15.0 & $\mathrm{C}_{15} \mathrm{H}_{24}$ & 1.4 \\
\hline 9 & Aristolene & 15.2 & 15.2 & $\mathrm{C}_{15} \mathrm{H}_{24}$ & 4.5 \\
\hline 10 & alpha-Gurjunene & 15.2 & 15.2 & $\mathrm{C}_{15} \mathrm{H}_{24}$ & 6.7 \\
\hline 11 & ${ }^{1} \mathrm{H}$-Indene & 15.5 & 15.4 & $\mathrm{C}_{12} \mathrm{H}_{2} \mathrm{O}$ & 2.0 \\
\hline 12 & Aromadendrene & 15.7 & 15.7 & $\mathrm{C}_{15} \mathrm{H}_{24}$ & 2.1 \\
\hline 13 & Hexamethylbenzene & 16.2 & 16.2 & $\mathrm{C}_{12} \mathrm{H}_{18}$ & 5.6 \\
\hline 14 & Aromadendrenepoxide & 17.2 & 17.2 & $\mathrm{C}_{15} \mathrm{H}_{24} \mathrm{O}$ & 9.2 \\
\hline 15 & Junipene & 17.5 & 17.5 & $\mathrm{C}_{15} \mathrm{H}_{24}$ & 3.4 \\
\hline 16 & 2-Naphtha-leneethanol & 18.0 & 18.0 & $\mathrm{C}_{15} \mathrm{H}_{24} \mathrm{O}$ & 6.7 \\
\hline 17 & valerenal & 19.2 & 19.2 & $\mathrm{C}_{15} \mathrm{H}_{22} \mathrm{O}$ & 0.8 \\
\hline 18 & tetradecanoic acid & 19.2 & 19.2 & $\mathrm{C}_{14} \mathrm{H}_{28} \mathrm{O}_{2}$ & 0.6 \\
\hline 19 & pentadecanoic acid & 20.1 & 20.1 & $\mathrm{C}_{15} \mathrm{H}_{30} \mathrm{O}_{2}$ & 0.8 \\
\hline 20 & hexadecanoic acid & 21.1 & 21.1 & $\mathrm{C}_{16} \mathrm{H}_{32} \mathrm{O}_{2}$ & 3.3 \\
\hline 21 & 1,5-diphenyl-3-pentanone & 22.5 & 22.5 & $\mathrm{C}_{17} \mathrm{H}_{18} \mathrm{O}$ & 2.1 \\
\hline
\end{tabular}

aThe retention time obtained from computer matching against with library; bthe retention time obtained from sample as shown in each peak of chromatogram 
identified in agarwood oil by many reports (Mei et al., 2008; Bhuiyan et al., 2009). Therefore, agarospirol should be a marker compound of the agarwood oil from A. crassna. Agarospirol is used in the pharmaceutical industry for sedative (Takemoto et al., 2009; Okugawa et al., 1996). Aristolene and benzyl-acetone demonstrate positive effects on the central nervous system (Okugawa et al., 1996). 10 epi-gamma-Eudesmol and junipene present sweet woody odor and are used in the fragrant industry (Takemoto et al., 2009).

\section{Conclusion}

Hydrodistillation of essential oil from A. crassna at $120^{\circ}$ $C$ gave maximum agarwood oil yield of $611.7 \mathrm{mg} / \mathrm{g}$ dried wood in 64 hours. The agarwood oils obtained at higher temperature have better physical properties; darker color, heavier, higher strength of oil fragrance and longer adhesion to the human skin. Grading of agarwood oil could be performed by testing the physical properties as well as analysis of the chemical composition by GC-MS.

\section{Acknowledgements}

This work was supported by the Prince of Songkla University's graduate studies grant. Department of Chemical Engineering, Faculty of Engineering, and Prince of Songkla University are gratefully acknowledged for their kind supports. The researchers would like to thank the Krissana Cooperative Club, Trat, Thailand for the participation.

\section{References}

Abdullah A, Ismail NKN, Kadir TAA, Zain JM, Jusoh NA, Ali NM. Agar wood grade determination system using image processing technique. Proceedings of the International Conference on Electrical Engineering and Informatics, Institut Teknologi, Bandung, Indonesia. June 17-19, 2007, pp 427-29.

Adam RP. Identification of essential oil components by gas chromatography/quadrupole mass spectroscopy. 3rd ed. Allured Publishing, Carol Stream, IL. 2001, p 456.

Barden A, Anak NA, Mulliken T, Song M. Hearth of the Matter: Agarwood use and trade and CITES implementation for Aquilaria malaccensis, Traffic Network Report 1998-2000. TRAFFIC International, Cambridge, UK, 2000, pp 1-51.

Bhuiyan MNI, Begum J, Bhuiyan MNH. Analysis of essential oil of eaglewood tree (Aqulilaria agallocha Roxb.) by gas chromatography mass spectrometry. Bangladesh J Pharmacol. 2009; 4: 24-28.
Cassel E, Vargas RMF, Martinez N, Lorenzo D, Dellacassa E. Steam distillation modeling for essential oil extraction process. Indian Crop Prod. 2009; 29: 171-76.

Hidayat W, Shakaff AYM, Ahmad MN, Adom AH. Classification of agarwood oil using an electronic nose. Sensors. 2010; 10: 4675-85.

ISO 279. Essential oils: Determination of relative density at $20^{\circ}$ C- reference method. 2nd ed. International Organization for Standardization, Geneva, 1998.

ISO 280. Essential oils: Determination of refractive index. 2nd ed. International Organization for Standardization, Geneva, 1998.

Keller PE. Mimicking biology: Applications of cognitive systems to electronic noses. Proceedings of IEEE International Symposium on Intelligent Control/Intelligent Systems and Semiotics. Cambridge, MA, USA, 1999, pp 44651.

Koul VK, Gandotra BM, Koul S, Ghosh S, Tikoo CL, Gupta AK. Steam distillation of lemon grass (Cymbopogon spp.). Indian J Chem Technol. 2004; 11: 135-39.

Liu J, Wu J, Zhao YX, Deng YY, Mei WL, Dai HF. A new cytotoxic 2-(2-phenylethyl)chromone from Chinese eaglewood. Chin Chem Lett. 2008; 19: 934-36.

Mani S, Jaya S, Vadivambal R. Optimization of solvent extraction of Moringa (Moringa oleifera) seed kernel oil using response surface methodology. Food Bioprod Process. 2007; 85: 328-35.

Mei WL, Zeng YB, Wu J, Cui HB, Dai HF. Chemical composition and anti-MRSA activity of the essential oil from Chinese eaglewood. J Chin Pharma Sci. 2008; 17: 225-29.

Milojevič SZ, Stojanovič TD, Palič R, Lazič ML, Veljkovič VB. Kinetic of distillation of essential oil from comminuted ripe juniper (Juniperus communis L.) berries. Biochem Eng J. 2008; 39: 547-53.

Naef R. The volatile and semi-volatile constituents of agarwood, the infected heartwood of Aquilaria species: A review. Flavour Frag J. 2011; 26: 73-87.

Okugawa H, Ueda R, Matsumoto K, Kawanishi K, Kato A. Effect of jinkoh-eremol and agarospirol from agarwood on the central nervous system in mice. Planta Med. 1996; 62: 26.

Pojanagaroon S, Kaewrak C. Mechanical methods to stimulate aloes wood formation in Aquilaria crassna Pierre ex H.Lec. (kritsana) trees. Acta Hortic. 2005; 676: 161-66.

Sovová H, Aleksovski SA. Mathematical model for hydrodistillation of essential oils. Flavour Fragrance J. 2006; 21; 881-89.

Takemoto H, Yagura T, Ito M. Evaluation of volatile components from spikenard: Valerena-4,7(11)-diene is a highly active sedative compound. J Nat Med. 2009; 63: 38085 .

Treybal RE. Mass transfer operations. 3rd ed. McGraw-Hill, New York, 1975. 